\title{
The impact of COVID-19 on the Canadian Kidney Paired Donation program: an opportunity for universal implementation of kidney shipping
}

Thomas B. McGregor, MD

Alp Sener, MD, PhD

Kathy Yetzer, BComm, BSC(Pharm)

Clay Gillrie, RN, MSN

Steven Paraskevas, MD, PhD

Accepted Aug. 12, 2020

Correspondence to:

T. McGregor

Department of Urology

Queen's University

76 Stuart St

Victory 3-4-222

Kingston ON K7L 2 V7

Thomas.mcgregor@Kingstonhsc.ca

DOI: $10.1503 /$ cjs. 012620

\section{SUMmarY}

"Never let a good crisis go to waste." - Sir Winston Churchill

The value of Canada's Kidney Paired Donation program to the population cannot be overstated. Its greatest challenge as a national program, however, is the geographic separation of recipient and matched donor. Representatives from every transplant program in the country have been working toward increased use of kidney shipping in order to diminish the disincentive of donor travel. With transplantation program and travel restrictions in place to minimize the risk of coronavirus disease 2019 (COVID-19), the time to make a full transition from donor travel to the shipment of donor kidneys has clearly arrived.

ince its inception in 2009, The Canadian Kidney Paired Donation (KPD) program, administered by Canadian Blood Services and involving the efforts of all kidney transplant programs in the country, has allowed 742 Canadians to benefit from living donor kidney transplantation. They would otherwise have remained on waiting lists for deceased donor organs or would never have received a transplant because of the lack of a compatible living donor. The KPD program has benefited particularly from the efforts and generosity of 55 non-directed anonymous donors, volunteers who have undergone surgery to donate a kidney without specifying a recipient. Each of these donations has been used to create chains of up to 6 transplants, amplifying the benefit of the donation. Recognizing the prevalence of renal failure in Canada, the survival and quality of life benefits of kidney transplantation compared with dialysis, and the superior outcomes of living donor transplants compared with deceased donor transplants, the value of an active KPD program to the Canadian population cannot be overstated.

A topic of debate over the past few years has been the implementation of shipping of living donor kidneys within the program. One of the main reasons for the success of the KPD program is the ability to match transplant candidates to potential donors anywhere in the country, thus improving the opportunity for finding a medically suitable donor for recipients in the program. However, this opportunity also leads to one of the greatest challenges we face as a national program: the geographic separation of recipient and matched donor. To address this, either the donor can travel to the recipient hospital to donate, or the nephrectomy can take place at the donor's "home" hospital, with the kidney then shipped to the recipient hospital for transplantation. Since its inception, the KPD program has primarily used the travelling donor model to minimize cold ischemic time (CIT).

In contrast to the Canadian experience, the majority of KPD programs worldwide use the kidney shipment model as it provides many important donor-centric advantages, including the convenience of donating at a hospital close to their home where their support system of family/friends is more likely to be available; reduced stress of travelling to an unknown city, hospital and medical team to undergo 


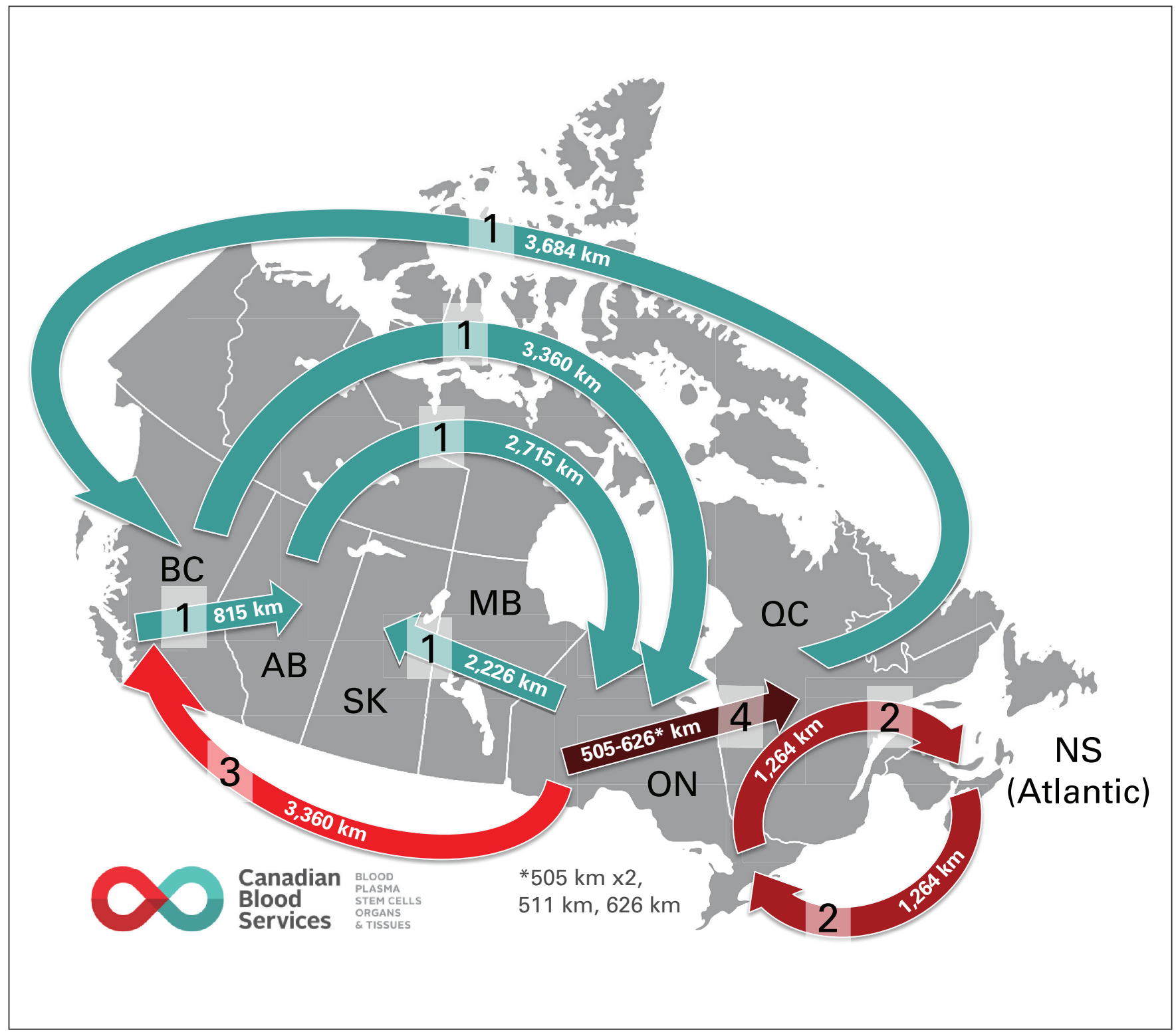

Fig. 1. All kidneys that have been shipped as part of KPD within Canada $(n=16)$. Figure used with permission from Canadian Blood Services.

surgery; and decreased travel-related expenses. None of these programs face the magnitude of the geographic challenges of a country the size of Canada. While 16 kidneys have been shipped interprovincially since 2010, we do not know how many potential living donors avoided donating because of the requirement for donor travel (Fig. 1).

Recently, Canadian Blood Services tasked surgical representatives from every transplant program to work together toward increased use of kidney shipping in order to diminish the disincentive of donor travel. The Kidney Surgical Subcommittee was formed with representation from each transplant program in Canada and has worked to address the challenges and barriers to this concept, while assuring the safety and successful use of shipped living donor kidneys. With basic rules of engagement set out, transplant surgeons from each program agreed to move toward shipping kidneys whenever possible. Additionally, Air Canada has continued to support the safe transport of organs on their flights, minimizing the need for expensive charters.

The coronavirus disease 2019 (COVID-19) pandemic has led to the temporary closure of many kidney transplant programs globally, and in mid-March the KPD program suspended all activities, resulting in some transplants being placed on hold. Canadian hospitals are now starting to resume living donor kidney transplantation, including those in the KPD program. Currently, having patients travel to donate their kidneys would be very difficult because of public health recommendations and would place both donors and transplant candidates at risk. In this 
current context, some provincial borders remain closed, and unessential travel on public transportation is discouraged; in particular, air travel has been limited and will remain so for the foreseeable future. Exchange of patients between hospitals for donation and transplantation may never be the same. Hospitals remain guarded to entry of patients, especially those from out of province, and visitors are often prohibited. Donors themselves will feel uneasy and unsafe having to fly, stay in an unfamiliar hospital in a different city or province and recuperate for several days postdischarge in a hotel, all of which would be viewed as unnecessary exposure and risk for infection with severe acute respiratory syndrome coronavirus 2 (SARSCoV-2), the virus that causes COVID-19.

The time to make a full transition from donor travel to the shipment of donor kidneys has clearly arrived. To implement this change, transplant programs and surgeons will need to work together to ensure that institutional guidelines and metrics during COVID-19 are met, shipping logistics are streamlined, and CIT minimized to ensure safe, equitable and successful outcomes. A procedure that begins on the west coast may finish many hours later on the east coast, and will require careful and clear communication among surgeons, physicians, nurses, administrators, airlines and many other personnel.

With crisis comes opportunity for change and growth; now is the opportune time to embrace kidney shipment for this important and collaborative program.

Acknowledgement: The authors thank the Kidney Surgical Subcommittee.

Affiliation: Organ donation and transplantation, Canadian Blood Services.

Competing interests: None declared.

Contributors: All authors contributed substantially to the conception, writing and revision of this article and approved the final version for publication. 